\title{
ACERCA DE LOS ORÍGENES DEL PERONISMO \\ EN LA PROVINCIA DE CORRIENTES (1944-1948)
}

MARÍA DEL MAR SOLÍS CARNICER

Universidad Nacional del Nordeste / CONICET

Con este artículo, que retoma las ideas planteadas en nuestro capitulo incluido en La invención del peronismo en el interior del país II, queremos rendir un merecido homenaje a Dario Macor, que junto a César Tcach nos alentó permanentemente en el desarrollo de nuestras investigaciones.

Desde hace algunos años, historiadores de distintos puntos del país dieron cuenta de la diversidad y la complejidad del proceso de formación del peronismo en el interior ${ }^{1}$, en el que -como lo señalara César Tcach recientemente- ni la clase obrera constituyó su columna vertebral ni la oligarquía fue su adversario natural ${ }^{2}$. Con el propósito de sumarnos a esa empresa, en este artículo buscamos sintetizar algunos de los resultados de la investigación que estamos llevando a cabo sobre los orígenes del peronismo en la provincia de Corrientes, y de ese modo, aportar un elemento más al conocimiento del complejo fenómeno histórico y político que constituyó el peronismo3.

Corrientes es una de las primeras catorce provincias argentinas que hacia $1940 \mathrm{com}-$ partía muchos de los rasgos socioeconómicos seńalados para otros casos - una economía tradicional, debilidad del movimiento obrero y nulo movimiento inmigratorio-. Además, tenía una tradición política fuertemente marcada por el predominio de los partidos

1 Una de las primeras publicaciones que intentó sintetizar estas investigaciones fue la compilación de Darío Macor y César Tcach, La invención del peronismo en el interior del país, Santa Fe, Ediciones UNL, 2003.

${ }^{2}$ César Tcach, «Mitos sobre el origen del peronismo en el interior del país», en: La Voz del Interior, Córdoba, 13/10/2013. Disponible en: http://www.lavoz.com.ar/politica/mitos-sobre-el-origen-delperonismo-en-el-interior-del-pais.

${ }^{3}$ El mayor conocimiento de la diversidad de rasgos que adquirió el peronismo en el país trae consigo un desafío historiográfico: el de aspirar a algún tipo de síntesis que permita incluir en la denominada «historia nacional» los resultados de todos estos nuevos aportes, que la enriquecen, ofrecen matices y hasta nuevas explicaciones. Creemos que avanzar en estudios históricos comparados, una práctica aún poco habitual entre los historiadores, podría ser un camino en esa dirección. 
conservadores provinciales, puesto que había sido gobernada ininterrumpidamente -desde fines del siglo XIX-por los autonomistas o los liberales o los antipersonalistas (aliados a los autonomistas durante la década de 1930)4. A este conjunto de variables se agrega una peculiaridad: fue la única provincia argentina en la que el peronismo no consiguió acceder al gobierno tras las elecciones de febrero de 1946. En esas elecciones ganan los radicales por primera vez en toda la historia política de Corrientes 5 .

Esta situación excepcional -en el marco de la política nacional-, nos llevó a preguntarnos acerca de los rasgos que adquirió el peronismo correntino en sus orígenes y el impacto que tuvo la experiencia de la derrota electoral en su formación. Buscamos identificar a sus principales dirigentes, su extracción política, social e ideológica, y desentrañar los conflictos y tensiones que se suscitaron entre ellos durante el proceso de su organización interna inicial. Todo ello en el marco de una provincia en la que: a) los partidos conservadores -autonomista y liberal- tenían un muy fuerte y largo predominio; b) su economía estaba basada fundamentalmente en la explotación ganadera en grandes latifundios, las organizaciones sindicales eran muy débiles y se encontraban completamente desarticuladas; y c) su sociedad, aunque estaba marcada por una profunda desigualdad e importantes contrastes, presentaba a la religiosidad -y especialmente el tradicionalismo católico- como un rasgo determinante que atravesaba a todos los sectores.

${ }^{4}$ Los partidos autonomista y liberal eran dos fuerzas políticas conservadoras de origen provincial que habían gobernado Corrientes en forma ininterrumpida desde fines del siglo XIX, ya sea alternándose en el poder o unidos a través de un pacto. Aunque ambos respondían a una doctrina de corte liberalconservador se le reconocía al autonomismo una tendencia más popular. El radicalismo, que inició su actuación en la política provincial en 1909, nunca consiguió acceder al gobierno y se transformó en la principal fuerza opositora al conservadurismo. Véase: María del Mar Solís Carnicer, «Autonomistas, liberales y radicales en Corrientes. Actores, prácticas e identidades políticas en conflicto (1909-1930)», en: Prohistoria, año XIII, № 13, Rosario, 2009.

${ }^{5}$ Esta cuestión -la derrota del peronismo en las elecciones provinciales de 1946- es la que generalmente llama más la atención del caso correntino. Sin embargo no es una pregunta difícil de responder puesto que está asociada al sistema electoral provincial construido de un modo muy particular y con una larga trayectoria que combinaba una peculiar división en secciones electorales con la representación proporcional y la elección indirecta del gobernador. El sistema estaba en vigencia desde 1893 y había facilitado la permanencia de los partidos conservadores en el gobierno. En 1946, simplemente se puso en funcionamiento una vez más y sirvió de freno al avance del peronismo en la provincia. Para mayores detalles sobre el sistema electoral provincial y la elección de 1946, véase: María del Mar Solís Carnicer, «La Argentina (casi) peronista. Las elecciones de 1946 en la provincia de Corrientes y la resistencia a la hegemonía», en: Estudios Interdisciplinarios de América Latina y el Caribe, vol. 20, № 2, 2009, Tel Aviv. 


\section{I) Las tres vertientes que dieron origen al peronismo correntino}

A partir de las investigaciones realizadas, apoyadas en distintos tipos de fuentes (prensa, documentos oficiales, entrevistas a diversos protagonistas y documentos privados) pudimos reconstruir el proceso que dio origen al peronismo en la provincia de Corrientes. De ese modo, conseguimos distinguir tres vertientes principales: el nacionalismo, el radicalismo antipersonalista y el sindicalismo.

\section{a) El apoyo nacionalista}

El núcleo nacionalista -constituido especialmente por los adherentes a la Alianza Libertadora Nacionalista ${ }^{6}(\mathrm{ALN})$ - fue el primer sector que rápidamente percibió la llegada de un movimiento político nuevo y uno de los principales apoyos ideológicos y políticos en los cuales se sustentó el primer peronismo correntino. La intervención federal liderada por David Uriburu ${ }^{7}$-en el año 1944- fue la que les permitió a sus adherentes acceder a los principales lugares de la esfera pública y del Estado.

La ALN, compuesta fundamentalmente por jóvenes de clase media, se identificó con el discurso político nacionalista que proponía Perón. Aunque no se adhirieron en bloque al nuevo movimiento, sí lo hicieron muchas de sus principales figuras y referentes. Este acercamiento entre nacionalistas y Perón se dio en todo el país, pero en el caso de Corrientes es llamativo el vínculo cercano que este grupo tuvo con el sector del laborismo, que generalmente es considerado el ala más progresista del primer peronismo.

Entre los colaboradores correntinos del interventor Uriburu, figuraron algunos simpatizantes o militantes del nacionalismo que más adelante tendrán una actuación destacada en el peronismo provincial. Muchos de ellos pertenecían a la ALN, que durante estos ańos alcanzó su mayor grado de popularidad en la provincia, especialmente entre los jóvenes disconformes con la política conservadora dominante. La ALN cobró especial

${ }^{6}$ La Alianza Libertadora Nacionalista se creó como un desprendimiento de la Alianza de la Juventud Nacionalista de 1937 pero con contenidos más radicalizados y con mayor capacidad de adhesión que la llevaron a convertirse rápidamente en un grupo de choque. En estos años, Juan Queraltó ejerció el cargo de Jefe de la Junta Nacional Ejecutiva. La ALN fue el primer movimiento nacionalista argentino en acercarse abiertamente a los sectores obreros. Véase: Daniel Lvovich, El nacionalismo de derecha, desde sus orígenes a Tacuara, Buenos Aires, Capital Intelectual, 2006.

7 David Uriburu, era una figura reconocida dentro del nacionalismo argentino, sobrino del ex presidente de facto Gral. José Félix Uriburu, había formado parte de su gobierno provisional como jefe de policía. Véase: Pedro Fernández Lalanne, Los Uriburu, Buenos Aires, Emecé, 1989, p. 462. 
protagonismo durante el transcurso de esta intervención, sus miembros participaban de los actos públicos con importantes columnas y sus dirigentes oficiaban de oradores privilegiados. Más tarde se sentirán atraídos por la propuesta del peronismo con el que van a encontrar muchas coincidencias ${ }^{8}$. Paralelamente, fueron los encargados de establecer contactos con los diferentes sindicatos llegando a conseguir importantes aliados en este sector, principalmente entre los trabajadores portuarios, de la construcción, de la energía eléctrica y del vestido?.

La crítica al liberalismo democrático, al imperialismo, la defensa de las tradiciones hispanas y católicas serán elementos que el peronismo heredará de los nacionalistas. Por este papel de iniciadores de un espíritu político nuevo y por su temprano apoyo al peronismo, se los suele denominar «chisperos del nuevo movimiento».

\section{b) El apoyo radical}

Otra de las vertientes que dieron origen al peronismo en Corrientes provino del radicalismo. La alianza que Perón buscó con diversos sectores radicales, finalmente la consiguió con Hortensio Quijano, un dirigente del radicalismo provincial que conformó la denominada Unión Cívica Radical-JR (Junta Renovación, primero, Junta Renovadora, después) y que acompañó a Perón en la fórmula presidencial, convirtiéndose en su vicepresidente.

Quijano era un destacado ganadero y antiguo dirigente radical, presidente de la Sociedad Rural de Resistencia (Chaco) que, aunque no había tenido una actividad política relevante, tenía cierto predicamento en el seno del partido a nivel provincial ${ }^{10}$.

${ }^{8}$ Entrevista a Gustavo Horacio Rey, ex integrante de la juventud de la ALN, Corrientes, 26/02 y 05/03/2008.

${ }^{9}$ Entre los sindicatos correntinos más cercanos al nacionalismo estaban principalmente el de los marítimos en sus diferentes secciones, el que nucleaba a los obreros de la construcción, el del vestido y el de los trabajadores de Luz y Fuerza. Asimismo, participaban asiduamente de las reuniones de la Alianza algunos dirigentes sindicales como Jerónimo García (panaderos), Juan Mihovilsevich (estibadores), Justo Ramón Alegre y Expedito Fernández (construcción) y Edmundo Viviani (del vestido). Estos temas los hemos trabajado en «La Alianza Libertadora Nacionalista y los orígenes del peronismo. Una aproximación desde la provincia de Corrientes (1944-1947)», en: Revista de Historia de América, № 141, México, Instituto Panamericano de Geografía e Historia, 2009.

10 Hortensio Quijano (1884-1952) era un radical oriundo de la ciudad de Curuzú Cuatiá (Corrientes). Se graduó de abogado en 1908 en la Universidad de Buenos Aires. Ejerció su profesión en la ciudad de Goya, donde también se dedicó a las actividades agropecuarias, siendo un activo contribuyente de la Sociedad Rural de Corrientes. Fue candidato a vicegobernador en las elecciones de 1919 representando al Radicalismo Disidente, en una fórmula encabezada por Miguel Sussini. Unos años después 
En ese momento formaba parte de la Unión Cívica Radical (Comité Nacional) de la que fue expulsado luego de aceptar el Ministerio del Interior en agosto de 1945 pero, en su trayectoria política anterior, siempre se había mostrado más cercano a los sectores antiyrigoyenistas del partido. A partir de la figura de Quijano y del interventor Ernesto Bavio (radical salteño), se empezó a organizar en la provincia el grupo radical que apoyaría la candidatura de Perón, consiguiendo armar este nuevo partido. Quienes lo constituyeron en Corrientes fueron, en general, radicales con algún tipo de participación política previa, no se trató de recién llegados sino de dirigentes con cierta trayectoria en el seno del radicalismo (especialmente del antipersonalismo) ${ }^{11}$. Pedro Díaz de Vivar, un médico perteneciente a una familia tradicional de Curuzú Cuatiá fue el candidato a gobernador por este sector en las elecciones de febrero de 1946.

Es notable que el rasgo más sobresaliente de la composición social de la dirigencia de la UCR (JR) sea la relación de continuidad con los partidos de los cuales provenían. Entre sus miembros es posible identificar a figuras relevantes de la política provincial, pertenecientes a familias de la élite con largo arraigo en la provincia. Además, es significativa la influencia del nacionalismo entre ellos, ya que muchos de sus dirigentes habían pertenecido a la $\mathrm{ALN}^{12}$.

El sector antipersonalista del radicalismo correntino fue el que más amplia y rápidamente se adhirió a esta nueva propuesta, situación que se reflejó en las declaraciones realizadas por sus dirigentes, preocupados ante la emigración de muchos de sus afiliados. El antipersonalismo, vinculado al sector conservador de la política correntina, ofrecía a los nacionalistas ciertos rasgos ideológicos coincidentes con su propia doctrina, que no sólo se reflejan en la participación de algunos de sus integrantes en la Legión Cívica en las décadas anteriores sino también en la compartida desconfianza en la democracia de masas. El acercamiento entre los sectores conservadores y los nacionalistas no era una

se trasladó al Territorio Nacional del Chaco y presidió la Sociedad Rural de Resistencia. Después del golpe de 1930 retornó a la actividad política acompañando a la línea presidida por Marcelo T. de Alvear. Véase: Antonio Emilio Castello, Hombres y Mujeres de Corrientes. Incompleto panorama para que se los reconozca y recuerde, Corrientes, Moglia ediciones, 2004, pp. 190-191.

${ }^{11}$ Un interesante relato de las reuniones realizadas en Corrientes bajo la dirección de Hortensio Quijano (h) puede leerse en Herminda María Bisson de Quijano, Los Quijano en mi vida. Fragmentos de mi vida y una visión atípica de la más reciente historia argentina, Corrientes, edición del autor, 1999. ${ }^{12}$ Entre los miembros de la UCR (JR) que integraron la ALN pueden mencionarse al médico veterinario Francisco Daniel Mendiondo, a los abogados Joaquín Díaz de Vivar, Florencio y Fermín Goitia, Juan T. Figuerero, Hugo Escalante Ortiz y Antonio Martínez Vidal y a los médicos Osvaldo Serrano y Felipe Germán Fages, todos ellos figuras muy reconocidas del ambiente político local. 
novedad ni una peculiaridad correntina, sino que se correspondía con una tendencia más amplia que venía desarrollándose desde fines de la década del '20 y que va a confluir en esta nueva agrupación afín a Perón ${ }^{13}$.

\section{c) El apoyo sindical}

Otra de las vertientes que dio origen al peronismo correntino provino del sector sindical, que a partir de la constitución de la Delegación de la Secretaría de Trabajo y Previsión (STyP), empezó a configurar-tal como ocurrió en todo el país- un partido político nuevo, el Laborista, con base sindical y constituido fundamentalmente por los trabajadores organizados y por los nuevos sindicatos que se crearon a partir del trabajo de la Secretaría.

Hacia 1940, el movimiento obrero en Corrientes era aún muy débil, los rasgos tradicionales de su economía basados fundamentalmente en la producción ganadera no habían favorecido la conformación de un sindicalismo significativo. Recién con el establecimiento de la Delegación provincial de la STyP en 1944, empezó a revertirse esa desarticulación. Allí, se destacó por su actuación el Teniente $1^{\circ}$ José Ramón Virasoro, un joven militar oriundo de Corrientes, que asumió la dirección de la Delegación en diciembre de $1944^{14}$.

Desde ese espacio, que reunió a los diferentes gremios de trabajadores correntinos, se irá gestando un sector político con base sindical. Es en el Partido Laborista -que se formó en Corrientes a fines de 1945- donde aparecen los nombres más desconocidos para la política provincial, reflejando la presencia de actores nuevos que se van a sumar a este movimiento. Sin embargo, es llamativa la ausencia de trabajadores en la fórmula propuesta por el laborismo para las elecciones de 1946: José Ramón Virasoro y Santiago Ballejos, este último un joven y entusiasta nacionalista, que había tenido participación en la organización de las luchas de los trabajadores tabacaleros del cam-

${ }^{13}$ Véase: César Tcach, «Entre la tradición conservadora y la tentación fascista: La derecha cordobesa contra Amadeo Sabattini», XI Jornadas Interescuelas / Departamentos de Historia, Tucumán, Universidad Nacional de Tucumán, septiembre de 2007, versión en CD-Rom; y María Inés Tato, «iAlianza estratégicas o confluencias ideológicas? Conservadores y nacionalistas en la Argentina de los años treinta", en: Cuadernos del CLAEH, № 91, Montevideo, 2005.

${ }^{14}$ José Ramón Virasoro era un joven militar correntino emparentado con familias de tradición liberal. Tuvo una actuación destacada en la Delegación de la Secretaría, donde personalmente se encargaba de recorrer la provincia para interiorizarse de la situación de los obreros y de los peones rurales. Datos obtenidos en la entrevista realizada a Carlos Gauna, su primo hermano. Corrientes, 18/04/2008. 
po goyano ${ }^{15}$. Ballejos era defensor de ideas nacionalistas y católicas, formaba parte de la Alianza Libertadora Nacionalista y había sido intendente de Goya durante la intervención nacionalista de David Uriburu en 1944. Ballejos ocupó ese mismo lugar en la fórmula gubernativa de la UCR (JR), siendo el único candidato que consiguió el apoyo de ambos sectores.

Las diversas versiones sobre el laborismo coinciden en afirmar su carácter democrático, progresista y renovador ${ }^{16}$, rasgos que sin embargo no aparecen con claridad en el laborismo correntino, en el que más bien se observa un estrecho vínculo con el nacionalismo. Una explicación posible a este rasgo distintivo podría ser consecuencia del bajo nivel de organización del movimiento obrero provincial antes del peronismo. De ahí que dirigentes con escasa o nula experiencia política buscaran el apoyo de los jóvenes y entusiastas nacionalistas quienes, contrarios a los partidos políticos tradicionales, vieron en el laborismo la posibilidad de una organización política distinta, que se acercaba al ideal de organización corporativa que ellos defendían.

\section{II) Las elecciones de 1946 en la provincia de Corrientes}

Como se seńaló en el apartado anterior, en las elecciones de febrero de 1946 el peronismo correntino (Partido Laborista y UCR-JR) presentó dos fórmulas distintas para la gobernación, aunque ambas coincidieron en el candidato a vice gobernador. $\mathrm{El}$ resultado del escrutinio fue muy particular pues, por un lado, la fórmula presidencial Perón-Quijano perdió de modo muy contundente frente a la propuesta por la Unión Democrática (37,5\% del peronismo frente al $62,5 \%$ de la Unión) pero, por otro, sus candidatos a diputados nacionales obtuvieron la representación por la mayoría. En las elecciones gubernativas provinciales, aunque el laborismo fue el partido que más votos consiguió en la elección primaria (20\%), en el Colegio Electoral todos los partidos opositores se unieron para votar a los candidatos del radicalismo que resultaron, entonces, los triunfadores; convirtiéndose Corrientes en la única provincia con un gobierno de signo político distinto al gobierno nacional ${ }^{17}$.

\footnotetext{
${ }^{15}$ El Liberal, Corrientes, 25/01/1946, p. 2.

${ }^{16}$ Véase por ejemplo Elena Susana Pont, El partido Laborista: Estado y sindicatos, Buenos Aires, CEAL, 1984; y Louise Doyon, Perón y los trabajadores. Los orígenes del sindicalismo peronista (1943-1955), Buenos Aires, Siglo XXI, 2006.

17 Véase: María del Mar Solís Carnicer, «La Argentina (casi) peronista. Las elecciones de 1946 en la provincia de Corrientes y la resistencia a la hegemonía», op. cit.
} 
En general, los resultados electorales de 1946 en Corrientes nos permiten inferir que se produjo un masivo pasaje de votos del antipersonalismo hacia la UCR (JR); que el autonomismo y el radicalismo fueron los dos partidos mayoritarios que más votos perdieron ante la aparición del peronismo, mientras que el liberalismo mantuvo su caudal electoral casi intacto. Es decir que además de los votantes nuevos, que indudablemente incorporó el peronismo, éste también recibió una importante transferencia de antiguos votos autonomistas y radicales ${ }^{18}$. Más allá de estos resultados en las elecciones primarias, la forma en la que estaba distribuida la representación de los departamentos en el Colegio Electoral hizo que esa representación variara considerablemente al traducirse los votos en escaños. Además allí, luego de varias negociaciones, todos los partidos opositores se unieron para votar a los candidatos del radicalismo ${ }^{19}$.

El fracaso electoral sorprendió negativamente a los peronistas correntinos y generó inmediatos conflictos internos en su seno. El más grave fue el que se dio en el laborismo en abril de 1946, cuando decidió expulsar de sus filas a Santiago Ballejos por inconducta y deslealtad partidaria, pues se comprobó que había iniciado gestiones con otros partidos para conseguir apoyos en el Colegio Electoral sin autorización de la Junta Ejecutiva del partido ${ }^{20}$. Seguidamente, Virasoro también presentó su renuncia como candidato y pidió su desafiliación al partido, pero ésta fue rechazada ${ }^{21}$.

${ }^{18}$ En cuanto a las elecciones gubernativas provinciales, el partido Laborista fue el que obtuvo el mayor número de sufragios, con 18.391 votos (19,9\%) se impuso en 8 de los 24 departamentos de la provincia (todos los de la costa del río Uruguay, además de Capital, Goya, Sauce e Itatí), el Partido Demócrata Nacional Distrito Corrientes (PDN-DC) obtuvo 13.660 votos (14,8\%) y se impuso en 6 departamentos, el Partido Liberal con 15.627 votos $(16,9 \%)$ y la UCR (JR) con 15.528 votos $(16,8 \%)$ ganaron en 4 departamentos cada uno, la UCR (CN) con 16.900 votos (18,3\%) se impuso en 2 departamentos mientras que el antipersonalismo con $5.785(6,3 \%)$ y el PDN (Autonomista) con 5.842 votos (6,3\%) respectivamente, no ganaron en ninguno de los departamentos del interior. Datos obtenidos en Nueva Época, Corrientes, 13/03/1946.

${ }^{19}$ Como el sistema electoral de la provincia era de representación proporcional y se combinaba con una singular división en Secciones Electorales, la diferencia entre cada uno de los partidos variaba considerablemente al traducirse los votos en escaños. Además, los antipersonalistas y el PDN (DC) votaron por la misma fórmula, lo que la convirtió en la más votada de la provincia. Aplicando el sistema de representación proporcional por cociente correspondieron 5 electores al PDN (DC), 6 a la UCR (CN), 1 al antipersonalismo, 4 al Partido Liberal, 2 al autonomismo, 4 al laborismo y 4 a la UCR (JR); mientras que los comunistas-PDP no obtuvieron representación en el Colegio Electoral.

${ }^{20}$ El Liberal, Corrientes, 22/04/1946 y Nueva Época, Corrientes, 23/04/1946.

${ }^{21}$ El Liberal, 07/05/1946. 
Esta crisis interna dentro del laborismo se profundizará cuando Perón decida, en mayo, disolver a los dos partidos políticos que lo habían apoyado en las elecciones y constituir el Partido Único de la Revolución. En realidad, en ese momento, el peronismo de todo el país estaba atravesando un proceso de organización interna, de múltiples negociaciones y discusiones políticas ${ }^{22}$. Corrientes no fue la excepción, aunque el hecho de ser partido de oposición y pretender la llegada de una intervención federal era un elemento que permitía acercar posiciones entre los dos sectores, ya que ésta era un anhelo compartido por ambas agrupaciones ${ }^{23}$.

Más allá de los intentos de unidad, dentro del peronismo correntino existían marcadas diferencias entre los dos grupos, como también conflictos internos en cada uno de ellos, especialmente en el laborismo. Estas diferencias quedaron explícitas en un acto organizado por un sector de ese partido el 17 de noviembre de 1946, en el que dejaron constituido el Partido Laborista Correntino y en el que se manifestaron en contra de la organización de un partido único ${ }^{24}$.

En enero de 1947 se conoció la noticia de que el Partido Único de la Revolución se iba a llamar Peronista y en marzo, el Consejo Superior del Partido Peronista designó a Sabino Acosta Monzón -en ese momento senador provincial- como organizador de la agrupación en Corrientes ${ }^{25}$. En abril se intervino la Delegación de la STyP y se designó como delegado interventor al rosarino Alejandro Giavarini. Con estas medidas -que respondían a la necesidad de limitar las luchas internas mediante el reforzamiento del criterio de autoridad personal como principio legítimo de construcción del partido-se buscó solucionar las diferencias surgidas entre las fracciones del movimiento ${ }^{26}$. A fines de enero, entonces, se realizó en la capital de la provincia un Congreso del Partido

\footnotetext{
22 Sobre los rasgos de este proceso véase Moira Mackinnon, Los años formativos del partido peronista. Buenos Aires, Siglo XXI-Instituto Di Tella, 2002.

${ }^{23}$ La actuación del peronismo como partido de oposición en Corrientes y el proceso que derivó en la Intervención Federal a la Provincia lo analizamos en: María del Mar Solís Carnicer, «Una provincia que está sola y espera. Peronismo en la oposición y antiperonismo en el gobierno: Corrientes, 1946-1947», en: Estudios, №22, Centro de Estudios Avanzados, Universidad Nacional de Córdoba, Córdoba, 2009.

${ }^{24}$ La presidencia de la Junta Ejecutiva del partido recayó en José Ramón Virasoro, Secretario General Juan Zamparolo, Vicepresidente primero Manuel Mora y Araujo (h), secretario del interior Alberto Fernández y secretario de actas Gerónimo García. El Noticioso, Corrientes, 01/12/1946, y El Liberal, 06/12/1946.

${ }^{25}$ El Noticioso, 16/01/1947, y El Liberal, 19/03/1947.

${ }^{26}$ La Mañana, Corrientes, 16/01/1947.
} 
Laborista Correntino, con asistencia de los miembros de la Junta Ejecutiva Provisional, presidida por José Ramón Virasoro, y los delegados departamentales. En esa reunión se dio por extinguido al partido y se aprobó la organización del peronismo en la provincia incorporándolo al partido nacional.

En paralelo a este proceso -y más allá de las diferencias internas-, los distintos sectores peronistas actuaron activamente en la oposición al gobierno provincial. Hicieron todas las diligencias que tuvieron a su alcance para conseguir la intervención federal y optaron por la abstención electoral en las elecciones provinciales de marzo de 1947, invocando su ilegalidad, por llevarse a cabo dentro de un gobierno que consideraban ilegítimo desde su origen. De ese modo, evitaron enfrentarse a una posible nueva derrota en las urnas, al tiempo que lograban extender los plazos para las negociaciones entre los diversos sectores con el propósito de alcanzar la unidad ${ }^{27}$.

Con la llegada de la intervención a la provincia en septiembre de 1947 se inició un doble proceso de reorganización, de las instituciones provinciales y del partido peronista, que creó una situación propicia para un triunfo electoral del peronismo en las elecciones que se realizaron a fines de 1948.

\section{III) La organización del Partido Peronista en Corrientes}

A principios de septiembre de 1947, y una vez instalada la intervención federal, se inició el proceso de definitiva organización del peronismo provincial con el objeto de prepararlo para un triunfo electoral. Se designó interventor federal al General Juan Filomeno Velazco, a quien lo acompañó como Ministro de Gobierno y Justicia, Santiago Ballejos (h). Velazco, a quien sugestivamente Joaquín Díaz de Vivar - diputado nacional por el peronismo- lo calificó de "pequeño führer provincial ${ }^{28}$, era un militar de carrera, oriundo de la localidad de Esquina (Corrientes), admirador del nacionalcatolicismo de carácter integrista, simpatizante del Eje y amigo personal de Perón. Por otra parte, estaba emparentado con familias tradicionales de la elite provincial pertenecientes al partido liberal. Había ocupado cargos clave en el gobierno provisional de Uriburu en 1930, en el que se desempeñó como Secretario del Ministerio de Guerra y Jefe de Seguridad de la policía de la Capital Federal. Después de la revolución de 1943 se le encargó la organización de la Policía Federal Argentina, convirtiéndose en jefe de dicha fuerza en

\footnotetext{
${ }^{27}$ María del Mar Solís Carnicer, «Una provincia que está sola y espera...», op. cit.

${ }^{28}$ Entrevista a Joaquín Díaz de Vivar, Archivo Historia Oral, Instituto Di Tella.
} 
1944. Ocupando ese cargo, fue el responsable de fuertes represiones a estudiantes en las manifestaciones que se realizaron en Buenos Aires con motivo del fin de la guerra $\mathrm{y}$ en contra de las medidas que el gobierno adoptaba en las universidades nacionales y colegios secundarios. Más tarde, tuvo una importante actuación en la jornada del 17 de octubre de 1945, protegiendo a las columnas de trabajadores que en masa se acercaron a la plaza de mayo solicitando la liberación de Perón ${ }^{29}$. En 1946, dirigió un partido denominado Independiente que se unió a la UCR (JR) y al laborismo para apoyar la elección de Perón ${ }^{30}$.

Muy pronto, el partido también fue intervenido, ocupando ese lugar el Diputado Nacional Antonio J. Benítez ${ }^{31}$. Bajo su dirección, el 9 de noviembre de 1947, se realizaron las elecciones internas de 18 convencionales para el Congreso General Constituyente del Partido que tendría a su cargo la tarea de redactar la Carta Orgánica, determinar su nombre definitivo y elegir sus autoridades ${ }^{32}$.

Se presentaron dos listas, la «verde» encabezada por Santiago Ballejos que recibió el apoyo de los municipios, de la Federación Obrera Provincial, de la UCR-JR, de una parte del laborismo y del gobierno de la Intervención Federal; y la «blanca» liderada por José Ramón Virasoro con el apoyo de un sector mayoritario del laborismo y de la Delegación Regional de la CGT. Quedaron, así, enfrentadas, las dos principales líneas

\footnotetext{
${ }^{29}$ Mientras ocupó el cargo de jefe de policía realizó actividades de espionaje contra los estadounidenses residentes en la Argentina durante la Segunda Guerra Mundial; terminada la guerra prohibió la realización de manifestaciones a favor de los aliados, y el 2 de mayo de 1945 protagonizó una dura represión contra un grupo de manifestantes que celebraban el triunfo de los aliados a los que amenazó con darles "confite» (acribillar). Era común escuchar en esa época entre los estudiantes y los manifestantes antifascistas la consigna «Que risa, que asco, la cara de Velazco». Fue una pieza clave en la organización del primer peronismo, a través un proceso de «peronización» de las fuerzas policiales. Véase, Martin Edwin Andersen, La policía. Pasado, presente y propuestas para el futuro, Buenos Aires, Sudamericana, 2002, pp. 133-146.

${ }^{30}$ Datos obtenidos de Raúl Héctor Barrios, Vida y Obra del General Juan Filomeno Velazco, Esquina (Corrientes), s/f, inédito; Elena Susana Pont, El partido Laborista: Estado y sindicatos, op. cit.; Entrevista a Joaquín Díaz de Vivar, Archivo Historia Oral, Instituto Di Tella.

${ }^{31}$ Antonio J. Benítez era correntino, oriundo de Esquina, había ocupado el cargo de Ministro de Justicia e Instrucción Pública de la Nación después de la revolución del 4 de junio, Asesor Letrado de la Policía Federal, Ministro del Superior Tribunal de La Rioja, Presidente de la Caja de Ahorro de la provincia de Tucumán, Profesor Titular de la Cátedra de Derecho de Navegación en la Facultad de Derecho y Ciencias Sociales de la Universidad de Buenos Aires. Diario del Foro, Corrientes, 28/10/1948.

32 Estas elecciones internas se realizaron en todo el país el 21 de noviembre, Corrientes fue el único distrito en el que se adelantaron.
} 
en las que se dividía el peronismo provincial en ese momento. La lista verde resultó triunfante por amplia mayoría de votos (21.052 votos contra 1.587 de la lista blanca). Virasoro denunció actividades dolosas por parte de funcionarios a favor de la lista ganadora, expresando que no se habían expuesto los padrones de afiliados y que en varios departamentos se había impedido a sus adherentes el acceso a las mesas receptoras de $\operatorname{votos}^{33}$. Las denuncias presentadas por Virasoro fueron desestimadas, y a partir de allí, éste perdió su posición dentro del partido. Ballejos se convertía, entonces, en uno de los dirigentes más prometedores del peronismo provincial.

Es claro que, para ese momento, Virasoro había perdido todo tipo de control sobre las «zonas de incertidumbre» más vitales del partido ${ }^{34}$, y que en el juego de intercambio vertical (entre líder y seguidores) no alcanzó a otorgar suficientes incentivos colectivos (identitarios) y selectivos (materiales). Ballejos, funcionario de la intervención, contaba con el apoyo económico de ésta y de la posibilidad de ofrecer mayores incentivos materiales (especialmente cargos) a sus seguidores. Virasoro, ni siquiera pudo ofrecer incentivos colectivos fuertes en un momento en que el mismo Perón buscaba diferenciarse del laborismo.

En enero de 1948, se reunió la Convención partidaria que aprobó la carta orgánica y la plataforma para el distrito Corrientes ${ }^{35}$. Allí mismo surgió la posibilidad de la futura candidatura a gobernador de Santiago Ballejos, que había crecido en popularidad a través del cargo de Ministro de Gobierno. Publicaciones en periódicos vinculados al peronismo y diversas asociaciones gremiales iniciaron una campaña a favor de su candidatura.

Esa situación generó una rápida competencia interna entre Ballejos y Velazco. Pero finalmente, en febrero de 1948 y después de buscar sin éxito el apoyo de Perón, Ballejos debió presentar su renuncia al ministerio, motivada en estas diferencias con Velazco y posteriormente fue condenado por traidor al peronismo y a su jefe ${ }^{36}$. La preferencia de Perón por Velazco no podría explicarse solamente por la relación de amistad que unía a ambos. En este sentido, no sería poco razonable pensar que la figura carismática de

${ }^{33}$ El Liberal, 10/11/1947 y La Provincia, Paso de los Libres, 14/11/1947.

${ }^{34}$ Ángelo Panebianco considera que los recursos del poder están ligados al control sobre áreas de incertidumbre organizativa, es decir aquellos factores que, de no ser controlados, amenazarían o podrían amenazar la supervivencia de la organización y/o la estabilidad de su orden interno. Véase Ángelo Panebianco, Modelos de Partido. Organización y poder en los partidos políticos. Madrid, Alianza, 1982.

35 Diario del Foro, 05/01/1948.

${ }^{36}$ Diario del Foro, 08/03/1948. 
Ballejos vislumbraba la posibilidad de que se convirtiera en un caudillo que en un futuro pretendiera competir con Perón dentro del partido, mientras que Velazco, soldado acostumbrado a obedecer órdenes, respondía a la idea de un dirigente subordinado a la estructura verticalista del peronismo.

Paralelamente, Velazco hacía tratativas con hombres de los partidos provinciales ${ }^{37}$. En un primer momento, buscó el apoyo de sus dirigentes consiguiéndolo solo parcialmente. Aunque no pudo cerrar ninguna alianza oficial, logró reducir electoralmente al autonomismo y que los liberales decretaran la abstención en todas las elecciones del período, eliminándolos de la competencia electoral ${ }^{38}$. Algunos importantes dirigentes del liberalismo fueron cooptados a través de su designación en puestos clave de la administración.

En abril de 1948 el interventor del partido comunicó la decisión del Consejo Superior de designar la fórmula gubernativa para Corrientes, compuesta por Velazco y Fernando Irastorza, así como también designó a los 32 candidatos a diputados provinciales y 16 candidatos a senadores provinciales ${ }^{39}$. Al día siguiente de las elecciones de diciembre, se expulsó del partido a Santiago Ballejos al comprobarse que había aconsejado a los peronistas de Goya votar por los candidatos de la UCR ${ }^{40}$. Durante la campaña, afiches con su imagen y la leyenda «El Perón Correntino» habían inundado las paredes de la capital ${ }^{41}$. La oposición abierta a un líder carismático implica automáticamente el final de la carrera política del oponente, tal como señala Panebianco ${ }^{42}$. A partir de ese momento, Ballejos no volvió a tener actuación política en la provincia.

Finalmente, en las elecciones del 5 de diciembre de 1948 -en las que el peronismo triunfó con el 61\% de los votos- quedó consagrada la figura de Juan Filomeno Velazco, como único líder del peronismo de Corrientes. Por su vinculación familiar con dirigentes liberales, por su carácter conservador desde el punto de vista ideológico, admirador del nacionalcatolicismo de carácter integrista, representaba la figura de un dirigente más compatible con la tradición política provincial y por ende, conseguiría más adhesiones y menos rechazos. Además, Velazco, era amigo personal de Perón y había colaborado con él desde los diversos cargos que se le encomendaron a partir de

37 Diario del Foro, 16/02/1948.

38 Diario del Foro, 05/03/1948.

${ }^{39}$ Diario del Foro, 22/04/1948.

40 Diario del Foro, 06/12/1948.

41 La Mañana, 06/10/1948.

42 Ángelo Panebianco, op. cit., p. 272. 
la revolución del 4 de junio de 1943. Estos antecedentes lo ubicaban en un lugar de privilegio en la estructura del peronismo y por ende, su figura y su liderazgo no podían discutirse ${ }^{43}$. En 1947, fue interventor federal en la provincia enviado por Perón y en marzo de 1949 se convirtió en el primer gobernador peronista de Corrientes. El periódico peronista El Diario del Foro, que durante los meses de la intervención federal había acompañado el proceso de organización partidaria y colaborado abiertamente en la construcción del liderazgo de Velazco, así describió su lugar en el peronismo provincial y nacional:

«Y es así como la Nueva Argentina vio nacer en las horas grávidas, junto al líder al hombre de la lealtad. También a su lado desde las horas primeras de la gestación hubo un sciudadano de la fidelidad. Este es el título que le corresponde a ese soldado de reciedumbre intangible que se llama J. Filomeno Velazco que con serenidad y firmeza, permitió, protegió y alentó el proceso histórico que nos llevaría al presente luminoso de hoy, dirigidos por el Gran Jefe Juan D. Perón, líder indiscutido. (...) El general J. Filomeno Velazco, puño de acero de la revolución, espíritu indomable y de la (fidelidad al General Perón, tiene merecimientos de sobra y legítimamente conquistados para gobernar a Corrientes (...) la honrará con las luces de su sabiduría y la madurez patriótica de su espíritu eminentemente nacionalista, como el de aquellos a quienes representa con su estampa de relieves puros de indomable argentinidad ${ }^{44}$.

Con Velazco, además, se consagraban en el peronismo provincial los principios ideológicos del nacionalismo y la identificación entre el peronismo, la religión católica $\mathrm{y}$ «la argentinidad».

Para ese entonces, el partido peronista se personalizaba cada vez más y la verticalidad se exhibía de un modo cada vez más acentuado. Las candidaturas, para cargos provinciales o nacionales, eran todas digitadas desde Buenos Aires y solamente tenían acceso autorizado al círculo interno del partido quienes gozaban del apoyo y la confianza de Perón. En ese contexto, la figura de Velazco se adaptaba con facilidad a los rasgos que iba adquiriendo el partido peronista, al tiempo que significaba para Corrientes sólo un cambio moderado de sus tradiciones y cultura política que le permitiría iniciar, aunque sin sobresaltos revolucionarios, una nueva etapa de su historia.

${ }^{43}$ Raúl Héctor Barrios, op. cit.; Elena Susana Pont, op. cit.; y Entrevista a Joaquín Díaz de Vivar.

${ }^{44}$ Diario del Foro, 04/03/1949 (el destacado es nuestro). 


\section{Consideraciones finales}

Conforme a lo desarrollado a lo largo del artículo, y desde una mirada que focalizó la atención en las dirigencias partidarias, estamos en condiciones de afirmar que el origen del peronismo en Corrientes se asentó fundamentalmente sobre tres bases: a) el aporte del radicalismo, principalmente antipersonalista «y en menor medida personalista», que constituirá la UCR-JR; b) el movimiento sindical que se nucleará a través de la Secretaría de Trabajo y Previsión y conformará el laborismo y c) el nacionalismo que, a través de la Alianza Libertadora Nacionalista, aportará dirigentes y militantes, además de una ideología y un discurso, en el que el catolicismo y el tradicionalismo constituirán los ejes centrales. Desde el punto de vista sociológico, cabe añadir, que el respaldo popular con que contó el peronismo en Corrientes no estuvo reñido con la relevancia que en sus niveles de dirección tuvieron miembros de la elite o de familias acomodadas.

Las dos agrupaciones peronistas que por separado se presentaron a las elecciones de febrero de 1946, fracasaron en sus intentos de llegar al poder provincial, convirtiendo a la provincia de Corrientes en la única con un signo político distinto al gobierno nacional. La derrota electoral -nunca asumida por los peronistas correntinos-, constituyó un acontecimiento crucial para el posterior proceso de configuración del partido; y la intervención federal a la provincia fue la herramienta de la que se valió el peronismo para la realización de los cambios que consideraban necesarios para conseguir su acceso al gobierno. La intervención fue un reclamo de los peronistas correntinos desde el mismo momento en que se conocieron los resultados de la elección de 1946. Este deseo -compartido por laboristas y radicales renovadores- se tradujo en una práctica política desestabilizadora y, en ese marco, se inscribió su convocatoria a la abstención electoral en los comicios legislativos de marzo de 1947. Por otra parte, la presencia de la Alianza Libertadora Nacionalista, generó «condiciones de recepción» favorables al perfil ideológico y tipo de práctica política desarrollada por el peronismo provincial. La fuerza de un nacionalismo hostil a la democracia política y al sistema de partidos, fue otra de las singularidades que caracterizaron la formación del peronismo en Corrientes.

La elección del general Velazco - ex jefe de la Policía Federal y «puño de acero de la revolución»-, como interventor federal primero y como candidato a gobernador después, constituyó un claro símbolo del rumbo que se buscaba darle al partido en Corrientes: una institución ordenada, jerarquizada, subordinada a las directivas del Consejo Superior, con una marcada identificación con el tradicionalismo católico y el nacionalismo. Su amplio triunfo en las elecciones de 1948 -cuyo análisis excede los límites del presente artículo- terminaría de dibujar el retrato del inicial peronismo de Corrientes. 